* Corresponding author

Phone +421556022470

E-mail address:roberthunady@tukesk

(Róbert Huňady, Ing. Ph.D)

Article information

Article history: AMS-Volume15-No.3-00112-11

Received 4 April 2011

Accepted 15 May 201

\section{Analysis of Causes Unwanted Dynamical Phenomenon on Output Pipes of Turbocompessor}

\author{
František Trebuňa, Róbert Huňady*, Miroslav Pástor, Binda Michal
}

Department of Applied Mechanics and Mechatronics, Faculty of Mechanical Engineering, Letná 9, 04200 Košice, Slovak Republic

\section{BIOGRAPHICAL NOTES}

František Trebuňa, Dr.h.c. mult. Prof. Ing. CSc. is a professor of applied mechanics, Dean of Faculty of Mechanical Engineering of Technical university of košice, Head of the Department of Applied Mechanics and Mechatronics. He is author of 9 monographs, 9 university textbook, special book publications, 12 university notebooks and more than 300 publications in journals and conference proceedings at Slovakia abroad. He is author of important projects and engineering works. He received several prizes at home and abroad. He received three honorary Doctor Honoris Causa (Dr.h.c.) including two from foreign universities for the development of applied mechanics and mechatronics.

Róbert Huňady, Ing. Ph.D. (1981) he received M.S. degree in mechanical engineering from Technical University of Košice, Slovakia in 2007. In 2009, he attended EC Marie Curie Training Program SIMVIA2 at Czech Technical University of Prague, Czech republic. He finished his doctoral study in study field Applied mechanics in Faculty of mechanical engineering at Technical University of Košice, Slovakia in 2010. Since 2010 he has been working as lecture at Department of Applied Mechanics and Mechatronics at Technical University of Košice, Slovakia. His professional activity is oriented into the area of modern optical methods of experimental mechanics such as high-speed digital image correlation, electronic speckle pattern interferometry and laser doppler vibrometry. He is author or co-author of more than 30 journals, conference papers and works aimed particularly at experimental modal and vibration analysis.

Miroslav Pástor, Ing. Ph.D. He is a senior assistant on the Department of Applied Mechanics and Mechatronics. In 2008 he received PhD. in the field of applied mechanics. He works on scientific and research projects on the department and publishes the results. He made remarkable work on the building of laboratories and on publication of monographs and university textbook at the department.

Michal Binda, Ing. received M.S. degree in applied mechanics from Technical University of Košice. He is currently working toward the Ph.D. degree in applied mechanics at Technical University of Košice, Slovakia. His research interests include modal analysis and vibrations. He has authored more than 10 journal and conference papers on these topics.

\section{KEY WORDS}

Experimental Analysis of Vibration, eigenfrequencies, output pipe of turbocompressor

\section{ABSTRACT}

During their operation the pipes of gas compressor stations are influenced by dynamic impacts caused by operating equipments as well as flowing media. Due to the occurrence of excessive vibrations on output pipes of turbocompressor after its 
modernisation, experimental vibration analysis of the output pipe of turbocompressors was realized, which included experimental modal analysis and vibration measurements during operating of turbocompressors.

\section{Introduction}

During the previous operation of gas compressor stations there were realized numerous repairs and modifications of compressors as well as distribution piping. Exchange of some components might cause initiation of vibrations of output pipes. During operation the distribution piping of compressor station is under intensive dynamic influence (pressure pulsation, whistle effect in the pipe branches, dynamic impulses caused by rotating parts of compressor, etc.) which have unsuitable influence on residual life of components as well as operational safety of machines (Trebuňa et al,2006, Trebuňa et al,2008). For that reason there are solved partial problems in order to decrease inconvenient influence realities mentioned above and extend the life components of compressor stations (Trebuňa et al,2007a, Trebuňa et al,2007b, Trebuňa et al,2004a, Trebuňa and Šimčák,2004b). For solution on practical problems are often used experimental methods of mechanics (Mseddi et al, 2011, Šimčák et al, 2010, Trebuňa and Šarga, 2011).

The paper presents experimental modal analysis of vibration of output pipes of two turbocompressors (marked as I and II) designed to increase gas pressure during its distribution by gas pipelines. Necessity of the experimental analysis resulted from owner requirement due to the fact that upgrading and reconstruction of turbocompressor I lead to initiation of excessive vibrations during its operation. The experimental analysis included modal analysis of output pipes of both turbocompressors as well as measurement of vibration of output pipes of turbocompressors during their operation.

\section{The experimental modal analysis of output pipes of turbocompressors}

Shape and position of output pipe (identical for both turbocompressors) is plotted in the Fig. 1a. In this figure are seen parts of output pipe lying over terrain.

The output pipe is joined to turbocompressor body by bolts and flanges. Under terrain level the pipe is lying on a base consisting system of springs and two bumpers (Fig. 2).
For measurement of eigenshapes and eigenfre-
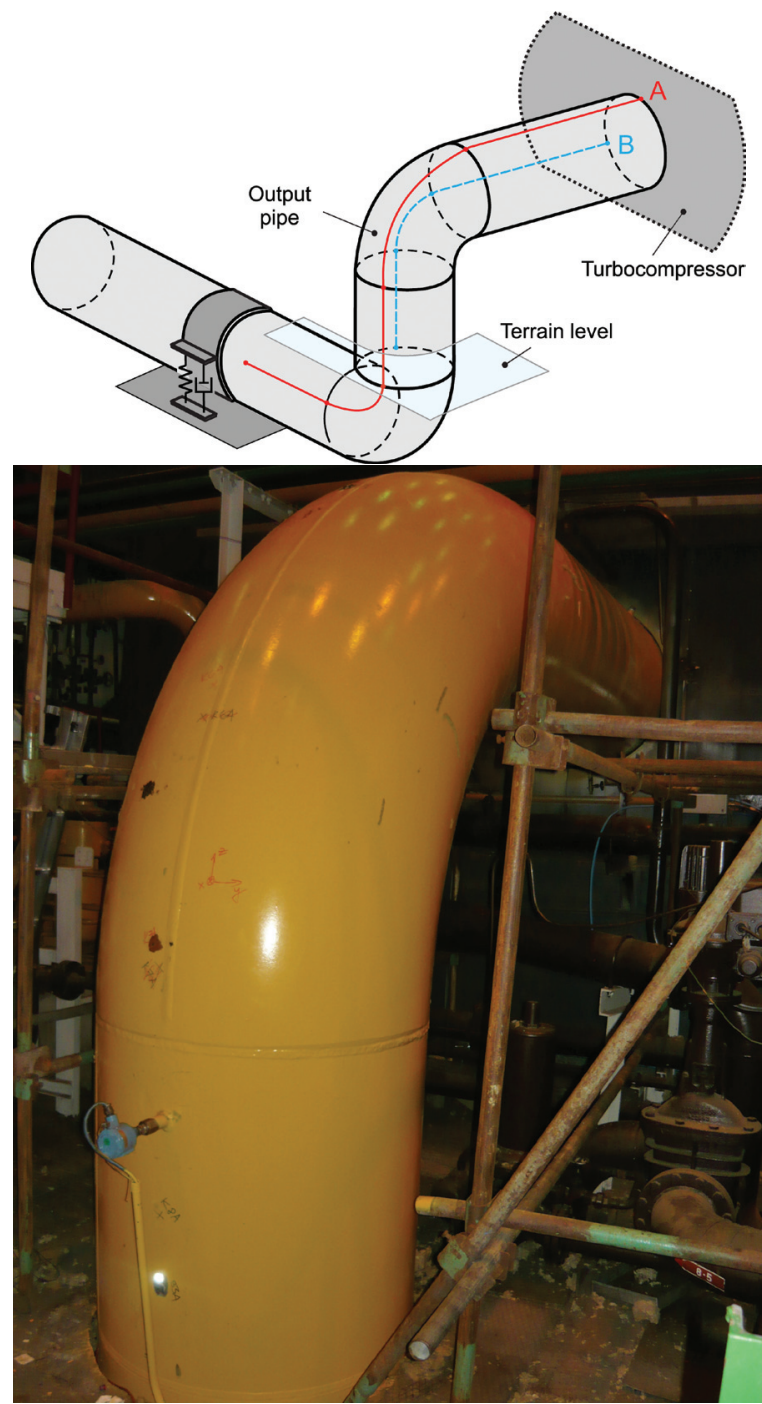

Fig. 1: Output pipe of turbocompressor. a) scheme of pipe, b) view at output pipe above terrain level (ground).

quencies of vibrated output pipe of turbocompressors I and II was used measurement system Bruel\&Kjaer Pulse 3560 (Trebuňa and Šimčák,2007c). Measurement of deflections was realized by threedimensional accelerometers Bruel\&Kjaer 4506B. The pipe was widebandly excited with impact hammer Bruel\&Kjaer 8210.

The frequency range of measurement was from 0 to $3.2 \mathrm{kHz}$, but relevant range aimed to evalua tions of modal testing was considered to be to $1 \mathrm{kHz}$. This frequency range can be excited by impact hammer with rigid head. There were created two geometry mod- 
els of pipe attached to both directions of exciting. In the Fig. 3 is shown scheme of accelerometers S1A and S1B positions and positions of exciting for both variants. Shape of geometry models of $A$ and B pipe is plotted in the Fig. 1a.

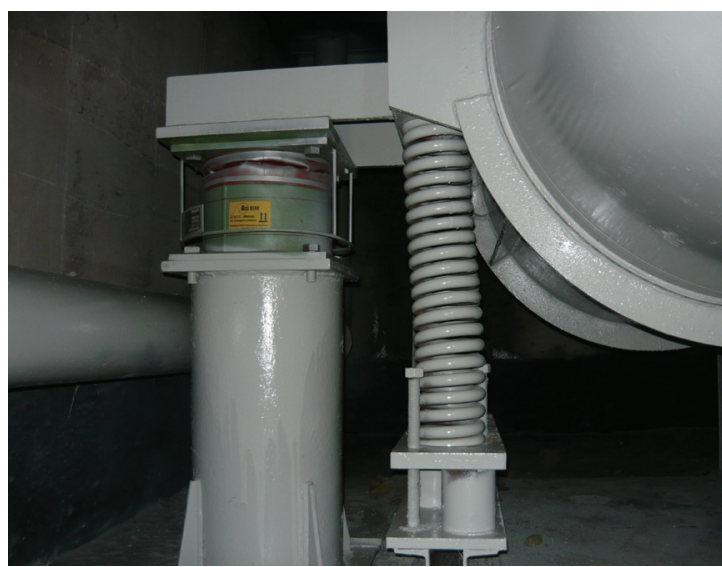

Fig. 2: System of springs and bumpers.

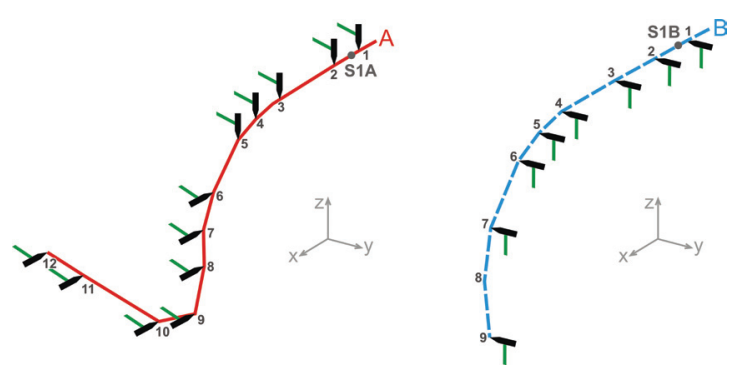

Fig. 3: Positions of applied accelerometers and excitations by impact hammer for geometric models $A$ and $B$ of output pipes of turbocompressors.

At the compressor station are three workingcompressors (placed in the row, marked I, II, III). During first phase experimental modal analysis on compressor I and II was continuously performed and compressor III was in full operation. There was the same pressure in output pipes of compressors I and II. Frequency response functions (FRFs) were gained for every exciting place and they were averaged in order to be able compare them (Žiaran,2006).

For illustration averaged frequency response functions - inertance are given in the Fig. 4 for measurement realized by accelerometer S1A (geometry model A of output pipes, Fig. 3).

Eigenshapes and eigenfrequencies were deter- mined by software application Pulse REFLEX. With regard to the fact, that eigenshapes of pipes demonstrate not only deformation of central line but also considerable deformation of cross section of pipe, it is impossible clearly determine sequence of shapes. This fact is supported also by numerical modal analysis. Eigenshapes and eigenfrequencies were estimated by means of software algorithms working on the basis of CMIF function (Complex Mode Indicator Function). The modal frequencies determined by method described above and analysis of stability diagrams for partial geometry models of both pipes are shown in the table 1 and table 2. These tables are called AutoMac matrixes of shapes. In the tab. 1 and tab. 2 relative similarity of partial shapes is determined by relative value of similarity, which may lie in range from 0 to 1. Value 1 represents 100\% similarity.
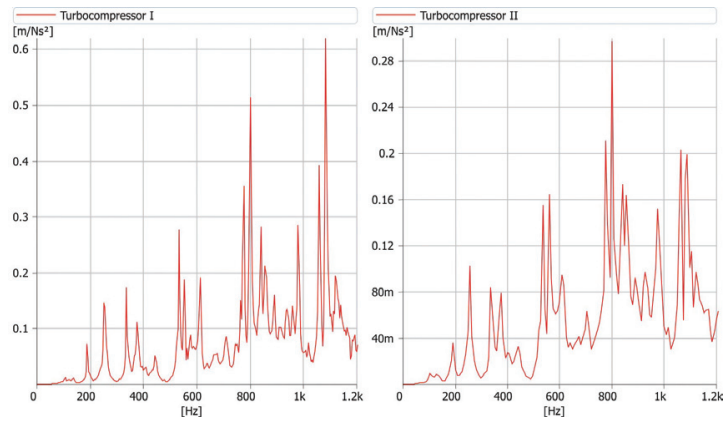

Fig. 4: Average frequency response functions - inertance direction.
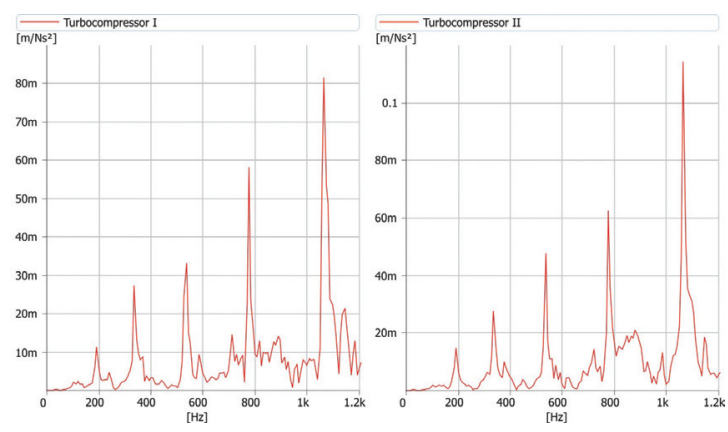

Fig. 5: Average frequency response functions - inertance direction.

The same procedure was performed in order to carry out experimental modal analysis for geometry model B of output pipes with accelerometer S1B (Fig. 3), while the same similarity was achieved for output pipe of turbocompressors I and II as was during previous measurement. For illustration, av- 
erage frequency response functions - inertance are compared in the Fig. 5 in y directions with accelerometer S1B.

During second phase the measurements were performed on turbocompressors I and II, while turbocompressor III was out of operation in order to prevent influence of the turbocompressor III to experimental modal analysis of pipes. However, it is necessary to know that during measurements there was pressure $0.1 \mathrm{MPa}$ inside output pipe of turbocompressor I and 5.9 MPa inside output pipe of turbocompressor II. This fact caused shift of natural frequencies to higher values by 10 to $30 \mathrm{~Hz}$.

Determination of modal shapes and natural frequencies of vibrations was realized by the same procedure as was during the first phase. The results obtained by measurement described above during second phase confirmed results obtained from measurement during first phase (there are small differences in frequency spectrum caused pressure inside pipes described above).

Table 1: MAC Matrix of modal shapes for the stability diagram (CMIF) of turbocompressor I at S1A.

\begin{tabular}{|lll|l|l|l|l|l|l|l|l|l|l|l|l|l|}
\hline $\mathbf{1 0 8 . 3 6 1}$ & $\mathbf{1 3 3 . 8 1 8}$ & $\mathbf{1 8 9 . 0 7 0}$ & $\mathbf{2 5 4 . 5 5 3}$ & $\mathbf{3 3 6 . 3 6 5}$ & $\mathbf{3 7 9 . 3 6 0}$ & $\mathbf{4 4 2 . 3 8 0}$ & $\mathbf{5 2 7 . 3 8 4}$ & $\mathbf{5 3 2 . 2 2 8}$ & $\mathbf{6 1 3 . 5 2 2}$ & $\mathbf{6 8 2 . 2 6 1}$ & $\mathbf{7 1 0 . 1 1 4}$ \\
$\mathbf{1 0 8 . 3 6 1}$ & 1.000 & 0.593 & 0.848 & 0.285 & 0.832 & 0.272 & 0.004 & 0.566 & 0.837 & 0.039 & 0.102 & 0.042 \\
$\mathbf{1 3 3 . 8 1 8}$ & 0.593 & 1.000 & 0.725 & 0.309 & 0.763 & 0.398 & 0.001 & 0.550 & 0.717 & 0.025 & 0.200 & 0.063 \\
$\mathbf{1 8 9 . 0 7 0}$ & 0.848 & 0.725 & 1.000 & 0.432 & 0.984 & 0.308 & 0.036 & 0.513 & 0.977 & 0.059 & 0.166 & 0.088 \\
$\mathbf{2 5 4 . 5 5 3}$ & 0.285 & 0.309 & 0.432 & 1.000 & 0.465 & 0.658 & 0.081 & 0.075 & 0.478 & 0.120 & 0.055 & 0.001 \\
\hline $\mathbf{3 3 6 . 3 6 5}$ & 0.832 & 0.763 & 0.984 & 0.465 & 1.000 & 0.363 & 0.030 & 0.516 & 0.985 & 0.060 & 0.147 & 0.075 \\
$\mathbf{3 7 9 . 3 6 0}$ & 0.272 & 0.398 & 0.308 & 0.658 & 0.363 & 1.000 & 0.146 & 0.080 & 0.376 & 0.130 & 0.030 & 0.024 \\
$\mathbf{4 4 2 . 3 8 0}$ & 0.004 & 0.001 & 0.036 & 0.081 & 0.030 & 0.146 & 1.000 & 0.105 & 0.044 & 0.787 & 0.301 & 0.215 \\
$\mathbf{5 2 7 . 3 8 4}$ & 0.566 & 0.550 & 0.513 & 0.075 & 0.516 & 0.080 & 0.105 & 1.000 & 0.512 & 0.278 & 0.470 & 0.091 \\
\hline $\mathbf{5 3 2 . 2 2 8}$ & 0.837 & 0.717 & 0.977 & 0.478 & 0.985 & 0.376 & 0.044 & 0.512 & 1.000 & 0.078 & 0.131 & 0.081 \\
$\mathbf{6 1 3 . 5 2 2}$ & 0.039 & 0.025 & 0.059 & 0.120 & 0.060 & 0.130 & 0.787 & 0.278 & 0.078 & 1.000 & 0.275 & 0.221 \\
\hline $\mathbf{6 8 2 . 2 6 1}$ & 0.102 & 0.200 & 0.166 & 0.055 & 0.147 & 0.030 & 0.301 & 0.470 & 0.131 & 0.275 & 1.000 & 0.239 \\
\hline $\mathbf{7 1 0 . 1 1 4}$ & 0.042 & 0.063 & 0.088 & 0.001 & 0.075 & 0.024 & 0.215 & 0.091 & 0.081 & 0.221 & 0.239 & 1.000 \\
\hline
\end{tabular}

Table 2: MAC Matrix of modal shapes for the stability diagram (CMIF) of turbocompressor II at S1A.

\begin{tabular}{|lll|l|l|l|l|l|l|l|l|l|l|l|l|}
$\mathbf{1 0 7 . 9 8 9}$ & $\mathbf{1 0 7 . 9 8 9}$ & $\mathbf{1 3 3 . 3 5 3}$ & $\mathbf{1 8 9 . 4 1 0}$ & $\mathbf{2 5 6 . 1 1 0}$ & $\mathbf{3 3 6 . 2 7 5}$ & $\mathbf{3 7 1 . 3 1 3}$ & $\mathbf{4 4 1 . 9 2 9}$ & $\mathbf{5 3 4 . 2 9 8}$ & $\mathbf{5 6 2 . 0 7 1}$ & $\mathbf{6 1 5 . 2 2 4}$ & $\mathbf{7 7 2 . 6 9 0}$ \\
$\mathbf{1 3 3 . 3 5 3}$ & 0.600 & 0.627 & 0.773 & 0.290 & 0.805 & 0.398 & 0.056 & 0.784 & 0.515 & 0.086 & 0.772 \\
$\mathbf{1 8 9 . 4 1 0}$ & 0.773 & 1.000 & 0.760 & 0.330 & 0.787 & 0.249 & 0.078 & 0.697 & 0.483 & 0.044 & 0.804 \\
$\mathbf{2 5 6 . 1 1 0}$ & 0.290 & 0.330 & 0.462 & 1.000 & 0.540 & 0.742 & 0.006 & 0.419 & 0.824 & 0.082 & 0.380 \\
$\mathbf{3 3 6 . 2 7 5}$ & 0.805 & 0.787 & 0.944 & 0.540 & 1.000 & 0.425 & 0.116 & 0.886 & 0.679 & 0.068 & 0.883 \\
$\mathbf{3 7 1 . 3 1 3}$ & 0.398 & 0.249 & 0.359 & 0.742 & 0.425 & 1.000 & 0.026 & 0.302 & 0.752 & 0.062 & 0.352 \\
$\mathbf{4 4 1 . 9 2 9}$ & 0.056 & 0.078 & 0.152 & 0.006 & 0.116 & 0.026 & 1.000 & 0.215 & 0.014 & 0.622 & 0.085 \\
\hline $\mathbf{5 3 4 . 2 9 8}$ & 0.784 & 0.697 & 0.911 & 0.419 & 0.886 & 0.302 & 0.215 & 1.000 & 0.551 & 0.172 & 0.758 \\
\hline $\mathbf{5 6 2 . 0 7 1}$ & 0.515 & 0.483 & 0.602 & 0.824 & 0.679 & 0.752 & 0.014 & 0.551 & 1.000 & 0.073 & 0.558 \\
\hline $\mathbf{6 1 5 . 2 2 4}$ & 0.086 & 0.044 & 0.092 & 0.082 & 0.068 & 0.062 & 0.622 & 0.172 & 0.073 & 1.000 & 0.041 \\
\hline $\mathbf{7 7 2 . 6 9 0}$ & 0.772 & 0.804 & 0.885 & 0.380 & 0.883 & 0.352 & 0.085 & 0.758 & 0.558 & 0.041 & 1.000 \\
\hline
\end{tabular}




\section{Operational modal analysis of vibration of output pipes}

Laser vibrometer PDV100T was used for measurement of operational vibrations of output pipes instead of accelerometers because amplitudes of deflection were out of range of accelerometer (Fig. 6). The scheme of measure chain is plotted in the Fig. 7. Operating vibrations were measured in $x$ direction at S3A (see Fig. 1a).

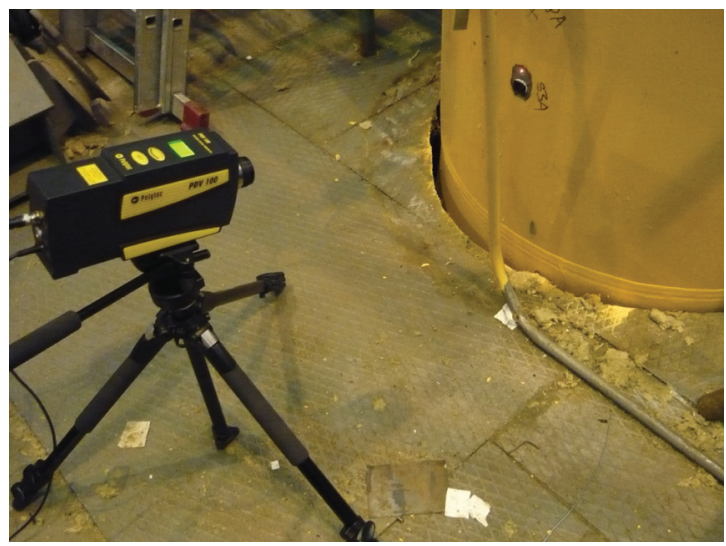

Fig. 6: Laser vibrometer Polytec PDV 100 during operational vibra-
The amplitudes of velocities of pipe vibrations were measured during full operation of relevant turbocompressor during $150 \mathrm{sec}$ in frequency range from 0 to $6.4 \mathrm{kHz}$. As a result of this measurement the average frequency spectrum of amplitudes of velocities of operating vibration was determined. Then final effective velocity of vibration was calculated according to standard STN ISO 10816-1 (STN ISO 10816-1,1999).

In the Fig. 8 are given frequency spectrums of velocity of vibrations of output pipes of turbocompressors I and II at S3A. In the table 3 and table 4 are shown effective velocities of operational vibrations of output pipes of turbocompressors I and II.

One part of experimental modal analysis was evaluation of influence of turbocompressor III to vibration of output pipes of turbocompressors I and II.

The analysis shows that dynamic effects caused by activity of turbocompressor III do not result to states in which critical increase in amplitude of vibration velocity of output pipes of turbocompressors I and II occure. tion measurement.

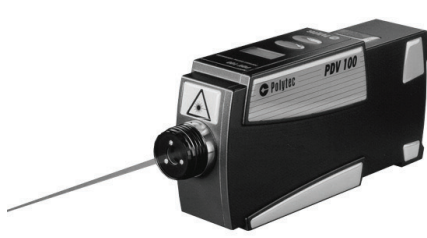

Laser Doppler Vibrometer Polytec PDV 100

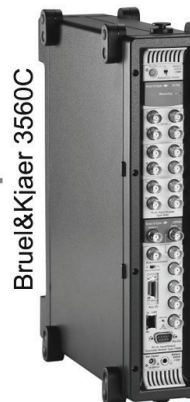

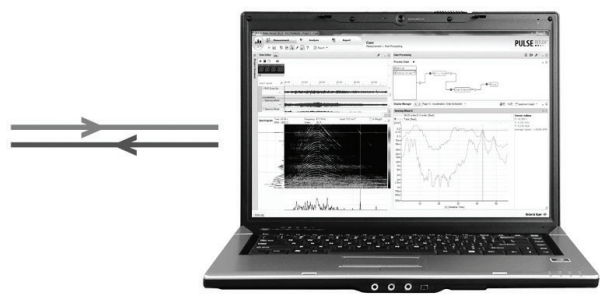

Bruel\&Kjaer Pulse Reflex ${ }^{\mathrm{TM}}$

Fig. 7: Scheme of measurement chain .

Table 3: Effective operating speed oscillations of output pipe of turbocompressor I.

\begin{tabular}{|l|l|l|l|l|l|l|l|l|l|}
\hline $\begin{array}{l}\text { Frequency [Hz] } \\
\text { Amplitude [mm/s] }\end{array}$ & 32 & 1536 & 1936 & 2304 & 2672 & 3072 & 3840 & 4608 & 5328 \\
\hline \begin{tabular}{l} 
The resulting effective velocity vef $[\mathbf{m m} / \mathbf{s}]$ \\
\hline
\end{tabular} & 3,958 & 25,667 & 2,486 & 6,097 & 1,905 & 5,619 & 4,456 & 1,579 & 1,194 \\
\hline
\end{tabular}

Table 4: Effective operating speed oscillations of output pipe of turbocompressor II.

\begin{tabular}{|l|l|l|l|l|l|}
\hline $\begin{array}{l}\text { Frequency [Hz] } \\
\text { Amplitude [mm/s] }\end{array}$ & 16 & 704 & 1424 & 2144 & 2848 \\
\hline \begin{tabular}{l} 
The resulting effective velocity vef [mm/s] \\
\hline
\end{tabular} & 2,484 & 2,076 & 7,487 & 1,513 & 1,517 \\
\hline
\end{tabular}



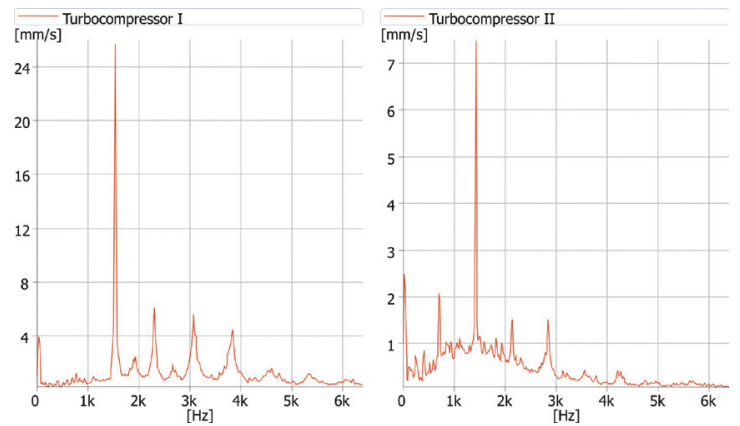

Fig. 8: Average velocity spectrum.

\section{Conclusion}

Based upon the measured values of modal and dynamic parameters of output pipe and subsequence comparison between parameters of turbocompressors I and II it can be stated that modal parameters (mainly natural frequencies) of output pipes of turbocompressors I and II are almost identical. Differences are expressed only in terms of modal frequencies gained during second phase of measurement, when the output pipe of turbocompressor II was pressurized, unlike pipe of turbocompressor I. These differences in values of modal frequencies were identified and quantified. The measurements also revealed the fact that response to excitation which is transmitted from environment (from turbocompressor III, etc.) is identical to both turbocompressors I and II and influence of the environment do not cause excessive deflections of vibrations of output pipes of turbocompressors I and II. Attention is attracted to higher components of operation amplitudes of velocity and acceleration during double blade frequency of turbocompressor I, which can be caused by not equal distribution of media around the perimeter of blade wheel or by releasing of bearing, bearing housing and foundations. On the basis of this, it is obvious that different behavior of output pipes of turbocompressors I and II can be caused only by turbocompressors themselves.

The measurements revealed fact that the resulting effective velocity of vibration of turbocompressor I is 7.92 mms-1. According to standard STN ISO 10816-1, annex standard B, table B1, for machine class IV, for value the resulting effective velocity of vibration the turbocompressor II is categorized into B-band, which includs machines intended for limited long term operation. The resulting effec- tive velocity of vibration of turbocompressor $I I$ is $26.803 \mathrm{mms}-1$. According to the above mentioned standard, it represents D-band in which values of vibrations are considered to be dangerous and can cause damage of machines. It follows that operation of turbocompressor I is unacceptable and it is necessary to reduce resulting effective velocity of vibration to value less than $11.2 \mathrm{mms}-1$ (STN ISO 10816-1,1999).

Based on shown above, according to the authors of this paper it is recommended to impose:

- Check the uniform distribution of medium around perimeter blade wheel of turbocompressor I,

- Check state of anchoring of turbocompressor I, mainly preload of anchor bolts and output pipe support included preload of springs,

- Execute measurement of vibrations on anchor bases of turbocompressor I and then to compare these results with results gained from turbocompressor II,

- Implement changes to output pipe of turbocompressor I so that they will enable changes in modal frequencies of output pipe caused by blade frequency and double blade frequency, respectively,

- To accomplish the measurement of modal and dynamic parameters repeatedly after changes on appliances.

\section{Acknowledgement}

The paper has been created realization of project "Centrum výskumu riadenia technických enviromentálnych a humánnych rizík pre trvalý rozvoj produkcie a výrobkov v strojárstve" (IMTS:26220120060), based on operating program support Research and Development financed from European Regional Development Fund and of project applied study - Stimuly "Komplexný modulárny robotický systém strednej kategórie s vyššou inteligenciou" (Req-00169-0001).

\section{References}

Mseddi, M., Driss, Z., Baccar, M., Abid, M.S. 2011. Computer Simulations of the Static State of the Turbocharger Turbine. Acta Mechanica Slovaca, Vol. 15, No. 2, 2011, pp. 70-79, ISSN 1335-2393

Šimčák, F., Berinštet, V., Štamborská, M. 2010. Some Possibilities of Determination of Yield Conditions for Cold Rolled Steel Sheets. Acta Mechanica Slovaca, Vol. 14, No. 4, 2010, pp. 28 35, ISSN 1335-2393 

Acta Mechanica Slovaca

Journal published by Faculty of Mechanical Engineering - Technical University of Košice

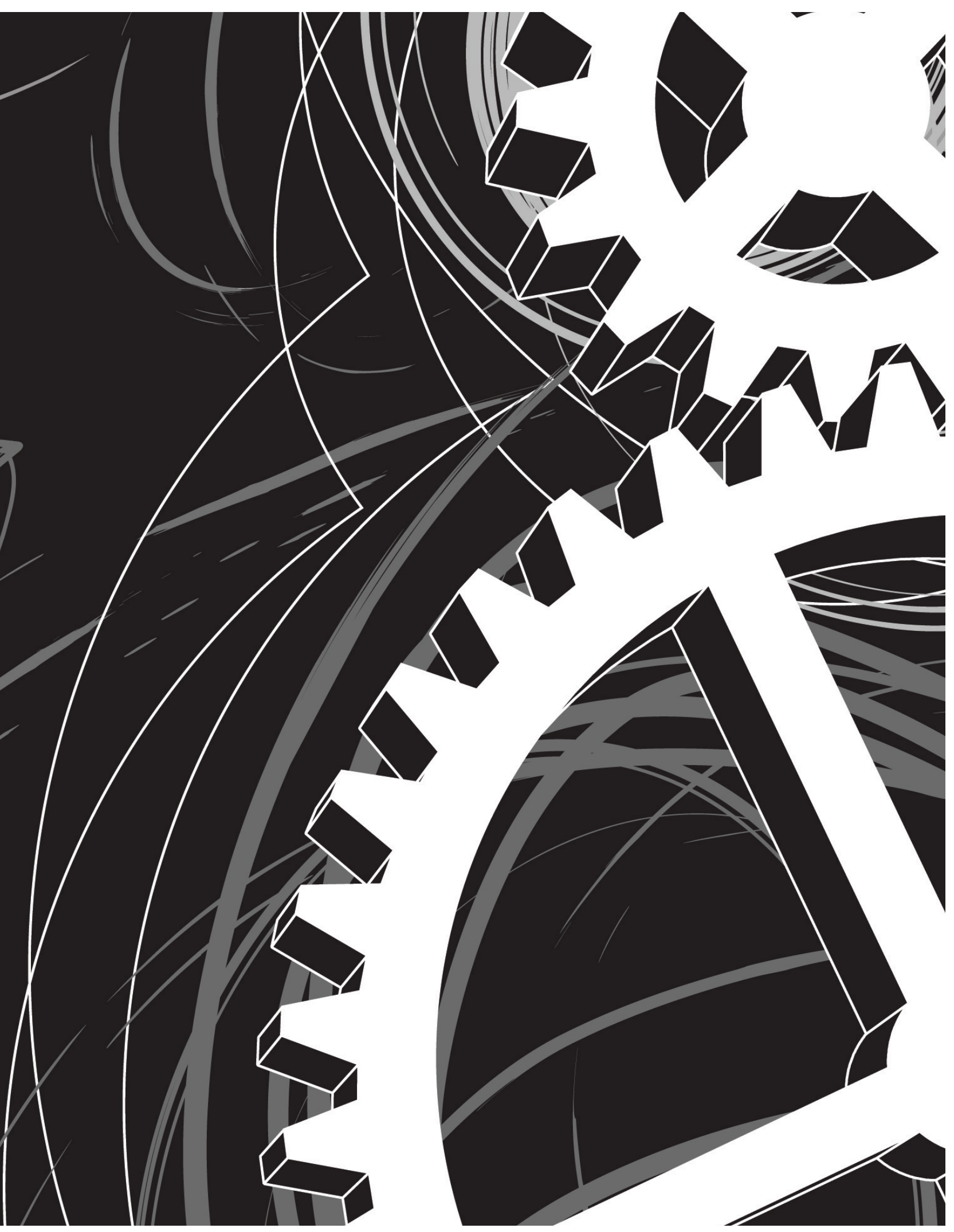

